\title{
Linking Knowledge Transformation to Information Systems Evaluation
}

\author{
Zahir Irani ${ }^{1}$ and Amir M. Sharif, \\ Information Systems Evaluation and Integration Network Group (ISEing), \\ Department of Information Systems and Computing, \\ School of Information Systems, Computing and Mathematics, \\ Brunel University, UK \\ Peter E.D. Love \\ We-B Centre, School of Management Information Systems \\ Edith Cowan University, \\ Churchlands, Pearson Street, Perth, WA 6018 \\ Australia.
}

\begin{abstract}
The evaluation and assessment of information systems (IS) is rapidly becoming an important and significant topic for study as well as practice. As such, the application of appraisal frameworks within technology management scenarios in industrial organizations, is vital to determining IS project success and / or failure. The information and knowledge requirements of evaluation appear to suggest that mapping benefits, risks and costs to organizational objectives and strategy, should result in a clearer and more rational appraisal process. However, in doing so, it is not clear from the extant literature within the field of IS evaluation, what aspects of knowledge relate to human and organizational factors in this decision-making task. Hence in order to elucidate this issue, the authors attempt to highlight those extant components of knowledge which contribute to the overall ISE process, within a case organization. This is achieved via an analysis of case study data against the well known knowledge transformation model proposed by Nonaka and Takeuchi. As a result of this, the authors present a model detailing these factors in the context of the IS evaluation lifecycle.
\end{abstract}

Keywords: Information systems evaluation, knowledge management, project lifecycle

\footnotetext{
${ }^{1}$ Corresponding Author: <Zahir.Irani@Brunel.ac.uk>
} 


\section{INTRODUCTION}

The efficient management and operation of business processes are considered closely aligned with the development of Information Technology / Information Systems (IT/IS) infrastructure. Indeed, the innovative development of IT/IS in manufacturing has evolved from a limited data processing perspective, to an expanded organisational-wide scope of computer-based manufacturing activities (Goldman et al., 1995; Ranky, 1990). Since the typical manufacturing lifecycle process involves the development and manufacture of an engineered product, from inception through to obsolescence, the selection and application of technologies that enable and support each of the steps in this lifecycle, is an important and necessary decision that can determine the success or failure of a company. IT/IS solutions such as Computer Aided Design (CAD), Enterprise Resource Planning (ERP), Computer Integrated Manufacture (CIM), Supply Chain Management (SCM), Customer Relationship Management (CRM) and eBusiness solutions, can help in the design, production and delivery of manufactured goods (Goldman et al., 1995; Tapscott et al., 1998; Sharp et al., 1999). In order to make the best use of these types of technology available to the organisation, the evaluation of IT/IS is seen as a vital and important task (Farbey et al., 1993).

Information systems evaluation is a decision-making technique which allows an organisation to benchmark and define costs, benefits, risks and implications of investing in IT/IS systems and infrastructures (Farbey et al., 1993; Remenyi et al., 2000). In supporting the justification of such technologies and infrastructures, investment appraisal and in particular, IS evaluation, plays a vital role via the use of such methods and techniques in evaluating the benefits, costs and risks of such capital expenditure (Irani et al., 2001; Remenyi and Smith, 1999; Remenyi et al., 2000). Many organizations use 'traditional' appraisal techniques, such as Return on Investment (ROI), Return on Capital Employed (ROCE), Cost Benefit Analysis (CBA) - regardless of their limitations (Ballantine and Stray, 1999; Remenyi et al., 2000). However, such methods are unable to accommodate the intangible benefits and indirect costs associated with an IT deployment (Hochstrasser and Griffiths, 1991; Irani et al., 1997; Irani and Love, 2001; Irani and Love, 2002). The process of evaluation exists across the complete IS lifecycle, and involves assessment against strategic goals and objectives, the use of an appropriate measurement technique and the capacity to feed back results into the enterprise (hence signifying a level of organisational learning).

The literature relating to IS evaluation shows that investment decisions tend to be influenced by organizational culture and the capacity for individuals within the organization to bring their knowledge and experience to bear on this given decisionmaking task. However, techniques for IS evaluation tend not to focus on the inherent information and knowledge dependencies involved. There is a need to not only understand basic principles of business but also a need to understand the specific nuances of a particular business (i.e. behavior and culture that is exemplified via implicit or tacit knowledge), and the benefits and limitations of information systems adoption across business processes (i.e. systems and processes exemplified via known or explicit knowledge). The scope and impact of such investment decisions therefore need to be based upon knowledge of the organization and its intended objectives and capabilities. In order to help mitigate some of the inherent risks associated with capital investments in technology, organizations need to leverage aspects of the organisational culture which may engender an environment that cultivates knowledge management. Given that knowledge is in itself an important aspect of information, this paper focuses on how knowledge is utilized and is transformed within a manufacturing organization, as a result of an IS evaluation task. 
Thus, as IS evaluation is a particularly knowledge-intensive task, it is likewise important to recognize the interplay between each of these knowledge forms. The authors of this paper therefore seek to map the knowledge within a manufacturing organization involved in an IS evaluation of an ERP implementation. A case study research strategy that employs qualitative research methods is used to define the scope of IT/IS in manufacturing and the role that evaluation plays in the decision-making lifecycle. A case description of the manufacturing organisation is presented, which highlights those aspects of stakeholder, internal learning, cultural and management issues, faced by the company as part of its IS evaluation experiences. As such, the research scope is therefore limited to an exploratory examination of those key facets which imply organizational learning also (within a knowledge management context). The authors carry out a mapping of the gathered case data knowledge factors and attempt to quantify these aspects against Nonaka and Takeuchi's well known Socialization, Externalization, Combination and Internalization (SECl) knowledge transformation model (Nonaka and Takeuchi, 1995). This comparison is carried out in order to verify the observed and extrapolated case data in terms of explicit and tacit knowledge forms. As a result of which the authors then present a synthesis of the research findings, in terms of a model which provides a context to the IS evaluation lifecycle as defined by Farbey et al. (1993). The paper summarily concludes with a set of learning outcomes and avenues for further research.

\section{KNOWLEDGE MANAGEMENT: OF THE EXPLICIT AND THE TACIT}

In order to address the issues of knowledge required and experienced within the IS evaluation task in the given case study company, it is first of all important to recognize the boundaries of knowledge. The contemporary understanding of this concept in business, management and information systems terms has been realized in recent times in the light of the growth of the field of Knowledge Management. As noted by many researchers and practitioners, Knowledge Management is a useful and powerful method for organizations to capture as well as utilize information and working practices via processes and tools which facilitate knowledge use (Davenport and Prusack, 1998; Probst et al., 2001). Many organizations which have adopted knowledge management techniques, have found that productivity and exchange of knowledge has enabled their company to maintain competitive advantage (Chauvel and Despres, 2002; Holsapple and Joshi, 1999). A traditional outcome of these frameworks and models, focuses on three key aspects (Leonard-Barton, 1995): people (organisational and cultural aspects of the use of knowledge); process (methods and techniques for managing the flow of knowledge); and technology (tools and infrastructure that assists in providing access to and exchanging knowledge). Throughout these aspects, a consistent theme has been to relate explicit and tacit forms of knowledge together.

Explicit knowledge can be said to be knowledge which is objective, theoretical, and can be said to be part of the world, i.e. relates to some object. Such knowledge is easily communicable and exchangeable (Davenport and Prusack, 1998; Wiig, 1997). Tacit knowledge on the other hand, is regarded as being knowledge which is in the most part, subjective and hidden. Hence, it can be said to be part of a person, i.e. relates to some subject and this is why it is difficult to formalize and communicate to others (Polanyi, 1967; Sveiby, 1997). As such, tacit knowledge is deeply rooted in the behaviors and actions of individuals, who have a commitment to a specific context (such as a particular area of expertise or series of work practices). These concepts basically describe tacit knowledge as socialized knowledge, which involves and requires some level of behavior plus intent, in order to describe it (Suchman, 1987; Whitley 2002). Given that it is also hidden within individual's behaviors and psychological makeup and actions, it is also quite difficult to understand when and where tacit knowledge is actually used. 
Perhaps of all of the researchers to define the nature of these forms of knowledge Nonaka and Takeuchi (1995), outline the manner by which tacit and explicit knowledge are interrelated. This approach to viewing knowledge, relies upon the notion that different levels of knowledge are required in order to carry out a task: explicit knowledge in the form of information and data; and tacit knowledge in the form of intuition and an individual's personal viewpoint. Where Polanyi did not make any categorical distinction in terms of the underlying relationship between explicit and tacit knowledge, the Japanese researchers chose to view explicit and tacit knowledge in terms of a dynamic relationship. As such they identified, four key processes relating to the transformation of one form to the other, in terms of a knowledge transfer process (tacit to explicit, explicit to tacit), known as the SECI model. Socialization is the process of sharing experience (creating tacit knowledge with others and across the organization); Externalization is the process of transferring or understanding tacit knowledge into explicit concepts; Combination is the process of converting or capturing explicit knowledge into systems and processes; and Internalization, is the process of converting or classifying explicit knowledge into tacit knowledge (and vice versa). The process of transferring explicit to tacit knowledge, can be thought of as a collaborative act, in that knowledge is transferred from the individual to the organization. The opposite can be said of the tacit to explicit transfer, which can be thought of as being based upon the idea that knowledge is somehow discovered by individuals, and then returned back into the organization.

Newman and Conrad (1999) and Kreiner (2000) have noted that the existence of knowledge, whether explicit or implicit (tacit), is reliant upon the user or consumer of such knowledge IT/IS facilitates in this. Hence, there is a need to reconcile the different forms of explicit and tacit knowledge within an organisational setting in order to extend the understanding of how such concepts exist and interact with each other. As such, the remainder of this paper therefore seeks to describe and analyze knowledge used within the ISE task in a manufacturing case study organization, and attempts to assess the SECI model as a tool for defining and assessing these knowledge forms.

\section{RESEARCH METHODOLOGY}

The multidisciplinary of IS research requires the exploration of quite different knowledge domains that are often underpinned by diverse epistemological stances. Walsham (1995) explains that a key task in developing a research design is to define the research approach being adopted by the investigative team. Events that form part of a life cycle evaluation process are conditioned by interrelated issues, such as time and culture, demonstrating that no two conditions are the same therefore, only allowing others to at best, draw similarities. As a result, interpretivist research that seeks to explore the links between knowledge management and the IS evaluation process, when grounded within a deep contextual analysis should be viewed as a valuable descriptive frame of reference rather than being prescriptive. With this in mind, the investigative team sough to draw from their previous experiences in conducting case based research. In doing so however, acknowledging that care needs to be taken in handing the rich, contextual data, which can be open to data bias and misinterpretation. As a result, a robust research methodology was constructed and acted as a blueprint to the research process and is presented in figure 1.

\section{Insert Figure 1 here}

Janesick (2000) explain that a qualitative research methodology can be split into three phases, which are reflected in Figure 1, and are namely, research design, data collection and data analysis. These constituent components are integral to the methodology adopted. 


\section{Research Design}

The first phase of the methodological process is the research design, where a critical review of the literature is conducted. It is here where the research scope, objectives and questions are defined thus, allowing the research to have direction. Then, the methodology is constructed where, the blue print for the research is planned. It is also here where the research strategy (Galliers 1992) and research methods (Weick 1984) are selected and developed, respectively. Then, the research protocol was developed, which acted as a tool to:

- Ask provoking questions of the research

- Ensure only appropriate data are collected

- Support the organization of data collection

- Schedule the research process

- Format the documentation of analysis

\section{Data Collection}

The data collection procedure followed the major prescriptions of the normative literature for doing fieldwork research (Dane, 1990; Fielder, 1978; Yin, 1994). Primary data were used to derive the findings presented in this paper, which included interviews, observations, illustrative materials (e.g., newsletters and other publications that form part of the case study organization's history), and archived documentation. A variety of secondary data sources were also used to collect data, such as internal reports, budget reports, and filed accounts that were later transcribed and formed the subsequent basis of qualitative content analysis (Mayring, 2000). The use of multiple data collection methods makes data triangulation possible, which enhances the reliability, validity and quality of data generated through using multiple research methods. In addition, methodological triangulation further improved the veracity of data generated through using multiple lines of enquiry.

\section{Data Analysis and Synthesis}

Miles and Huberman (1994) explain the difficulty in analyzing qualitative data. The authors made use of content analysis to support their classification of the data, as well as to construct meaning from the data. To operationalize the data analysis process, units of analysis and their sub-grouping were developed, which lied at the genesis of this enquiry. The units of analysis and their sub-grouping included:

- Scope and analysis of ERP Benefits
- Strategic
- Tactical
- Operational

- Issues encountered with the ERP implementation
- Information Systems Appraisal: approach and scope
- Employee Commitment
- Organisational Culture
- Training and Education
- Management Commitment

Each interview lasted approximately 1 hour and was conducted with:

- Managing Director (MD)

- Production Director (PD)

- Chief Financial Officer (CFO) and,

- Numerous shop floor operatives. 
The interviewer carefully ensured that the interviewees were fully informed about the purpose of the interviews, and took steps to put the interviewees at ease so that a two-way, open communications climate existed. Shaughnessy and Zechmeister (1994) suggest that interviewer bias needs to be addressed when carrying out qualitative research of the described nature, which often results from the use of probes. These are follow-up questions that are typically used by interviewers to get respondents to elaborate on ambiguous or incomplete answers. Care was taken to reduce bias to a minimum through refraining, as much as possible from asking leading questions. In trying to clarify the respondent's answers, the interviewer was careful not to introduce any ideas that may form part of the respondent's subsequent answer. Furthermore, the interviewer was also mindful of the feedback respondents gained from their verbal and non-verbal responses. The interviewer therefore avoided giving overt signals such as smiling and nodding approvingly. After every interview that was undertaken, notes were given to each person to check to resolve any discrepancies that may have arisen and eliminate any interviewer bias. This approach to interviewing has proved successful in similar type research as reported by Irani et al., (2001; 2005).

\section{CASE ENQUIRY}

The case organization studied in this research, Company $A$, is a manufacturing organization within the UK, which specializes in the manufacture of bespoke aerospace, automotive, and other engineering components. The development and growth of this company has largely been due to successful technology investment in the past. Figure 2 shows the context of the case and is now discussed in more detail.

\section{Insert Figure 2 here}

This diagram shows the internal and external pressures faced by Company $A$ at the time of conducting the research. In terms of how this view is presented, the internal factors are shown on the outside of the bounded rectangle, whilst the value chain of the organisation is shown inside this rectangle (based upon that as in Porter, 1985). As can be seen, there were fourteen key identified management and organisational factors ranging from decision-making, resource, IT/IS and training issues, impinging upon the company. These factors were identified and agreed to be major issues faced by the company by the MD, Production Director and CFO. In addition, the inherent value chain, i.e. core competencies of the organisation are shown at the centre of these impinging management-led considerations. As can be seen, Company $A$ is not much different from many other modern organisations, in that the motivations and goals of the business involve key aspects of IT/IS, market involvement, relationships with their customers, new product development and innovation, organisational culture and overall corporate strategy. What differentiates Company A from most other companies in its sector, is the focus on people, process and technology. Moreover, there was also a mandated focus on process improvement and IT/IS infrastructure enhancement as the basis for improving competitive advantage and instigating an appropriate environment for organisational learning.

The decision-making scenario that was investigated, involved the evaluation of an integrated Enterprise Resource Planning (ERP) system (Irani et al., 2001a; Sharif et al., 2005). At the time of conducting the case enquiry, this investment would enable Company A to maintain competitive advantage through the innovative use of this integrated manufacturing system. It was also understood that in doing so, any such investment would require a significant amount of support and training, for all those stakeholders involved in using the system and in benefiting from the results of the system. 


\section{Scope and Analysis of ERP Benefits}

Before embarking upon the investment in new technology, an attempt at categorizing the scope of benefits identified by the case study company management team, in terms of either strategic, tactical or operational benefits was carried out. In considering the scope of benefits to be achieved, the following pertinent issues were considered and included in a Cost Benefit Analysis (CBA) of the ERP system:

- Improved response to customer changes, product and service quality;

- Improved product management and development;

- Improved organisational teamwork;

- Improved integration with other business functions;

- Promotion of the concept of an 'open' proactive culture.

Hence, the following sections detail these strategic, tactical and operational benefits identified by the Managing Director (MD), Production Director, and Purchasing Director of Company $A$, a summary of which is given in Table 1.

\section{Insert Table 1 here}

It is interesting to note the diverse spread of benefits identified in Table 1, and that certain benefits were not considered by all interviewees as areas of substantial operational saving. As such, the MD commented:

"The scope of benefits appeared enormous and only restricted by my imagination ... I was sure the benefits would far outweigh the costs."

\section{Scope of Strategic Benefits}

In Company A, management mentioned that ERP would have to be deployed with strategic potential, or simply with the objective of providing operational process improvements. However, this similarity appears only between the two directors, although it may not be surprising that the Managing and Production Directors share the same vision of the strategic contributions that ERP can offer. The Production Director, who is responsible for implementing and tailoring many of the issues associated with ERP, was more aligned to the tactical/operational aspects of the project, and therefore did not take a holistic, or long-term view of the project, and its effects on the organization.

\section{Scope of Tactical Benefits}

Table 1 also shows the also shows the increase in number of Tactical benefits identified by the Production Director further down the benefit scale. Even so, the two directors identified many implications of ERP, which involved establishing 'production' related tactics that support strategic benefits. Regardless of their different natures, it was the focus and inclusion of tactical benefits such as improved teamwork, facilitating an 'open' culture, improved integration with other business functions, which were identified by the interviewees as very significant tactical resultants to investing in ERP.

\section{Scope of Operational Benefits}

Operational benefits are generally achievable in the short-term and affect, or result from changes in day-to-day operations (i.e. reduced raw material inventory). Although the benefit of reduced raw material was not identified as a substantial area of cost saving, the benefit of improved capacity planning was mentioned by all interviewees as an area of significant saving. A possible reason for the focus on benefits such as work-in-progress, increased productivity and reduced labor costs, might be that they easily translate into performance measures that can be financially quantified, to assess operational project success (and therefore, allowing tactical and strategic decisions to be implemented). 


\section{Issues encountered with the ERP implementation}

The following sections now outline those pertinent issues which were faced by the case study organisation in attempting to implement the given ERP system, based upon the preceding benefits and outcomes expected.

\section{Information Systems Appraisal: approach and scope}

Company A's approach to evaluating and assessing investments in projects, incorporated a typical financial accounting approach (Cost Benefit Analysis, CBA), which attempted to include human as well as costs and benefits. This had been used for appraising previous investments (such as for Computer Numerically Controlled, CNC, machinery), and was now to be applied to identify those benefits and costs associated with Production Planning and Control (PPC) and Shop Floor Data Collection (SFDC) modules. However, there was no structure to the analysis of those benefits and costs identified as would be likely in terms of the typical ISE lifecycle (Farbey et al., 1993). There were no assignments of financial values to the investment implications identified. Company A's prescriptive justification process soon proved itself inappropriate, as it was unable to quantify and qualify the intangible and non-financial benefits, and indirect costs.

As a result, an 'act of faith' investment appeared to be the only option available, mainly due to the inexperience of the new management team, who were unaware of how to use non-traditional ISE techniques. Company A later conceded the failure of their vendor PPC/SFDC system, and as a result, then set about developing their 'own' business solution, modifying their earlier CBA based on their experiences. Although, there was now a wider appreciation of the projects' human and organisational implications, Company A nonetheless developed bespoke ERP in the same vein (in part because they were unable to quantify benefits and costs yet again). The management team was also motivated to adopt this strategy because they saw the massive potential benefits such a system could bring to improving production control, throughput and teamwork, as detailed in Table 1. The business perspectives taken by Company $A$ have been summarized in Table 2, in terms of Innovation (i.e. strategic), Maintenance (i.e. tactical) and Support (i.e. operational) factors.

\section{Insert Table 2 here}

The given scope of the appraisal approach as defined in Table 2, although not completely formalized and adopted as part of rigorous ISE by the company, were seen to be an accurate reflection of the very much informal and ad-hoc decision-making process employed. It is interesting to note that operational considerations (support), were not seen or considered to be as vital to the company's future transformation plans. Therefore, management very much viewed project justification as a hurdle that had to be overcome, and not as a technique for evaluating the project's worth in any sort of rigorous terms. This had significant implications, as during the preparation of the ERP project's proposal, managers spent much time and effort investigating its technical and financial aspects (in a strategic sense), rather than risk and benefit aspects (in a tactical / operational sense).

The remaining project team members tried to address implementation and human resource risks, against estimated cost implications. So, whilst there was a desire to invest and implement in technology, there were, in a sense, opposing knowledge-based views of the justification process.

\section{Employee Commitment}

Specific stakeholder job functions and software types associated with the adoption of computerized PPC were identified by Company A. Yet the management team did not consult, or identify those operational stakeholders responsible for the relevant business 
processes. There was a lack of representation and involvement by any operational employees in the team that was responsible for selecting and implementing the initial vendor solution. There appeared to be a lack of interest and ownership by the operational workforce in computerizing business processes, as a result of this, and they did not accept, or use the 'prescribed' SFDC system. Also, they could not see the relevance, or business need to computerize PPC/SFDC, with attitudes of 'why change things' prevalent. The operational workforce thought that management had a 'hidden agenda' in implementing SFDC, in order to gather planned set-up and run times, therefore implying gathering of performance management data. Therefore, the issues associated with implementing PPC were addressed from a purely technical perspective, with Company A later realising the consequences of neglecting the 'softer' side of IT/IS implementation.

\section{Organisational Culture}

As Company A is a small manufacturing jobbing shop located in the North of England, the traditional engineering culture within the firm revolved around a union-based view of the worker-management relationship. As such, the work ethic culture of the firm was very much driven and was mired in a "them and us" culture, with a mild skeptical stance taken by most of the workers there. Thus the implementation and initiation of an integrated technology to address production and manufacturing control issues, was seen to be a solution to overcoming this cultural issue. One approach which was successful, was to evolve the managerial culture within the firm, from a dominating reactive senior management structure, which had a clear hierarchy and was dependent on traditional approaches to manufacturing - to one of a much clearer responsibility-led leadership style. However, the "buying-out" of two senior directors, and their removal from Company A's board, presented the organisation with a management experience void. In addition, other cultural factors also contributed towards Company A's PPC/SFDC system failure, the MD commenting that:

"People are not machines and need gentle persuasion, they have to buy into the Company's vision ... It has taken us years to gain their trust and commitments, which are essential in accepting change and the need to invest in new technology"

As a result, the firm's mission statement had changed to encompass a partnership between people, technology, customers and suppliers which therefore led to the observation:

"We used to have a very militant union that was always at logger-heads with management ... Just by looking around you can see how much things have changed, we don't have a union anymore ... Everyone works well together, and is proactive and empowered to get on with it [work]."

\section{Training and Education}

Company $A$ had done little training and education before their implementation of the PPC/SFDC (thought by the management team to have contributed towards the failure of their system). When Company A purchased their PPC software, the company got 5 day's worth of vendor training, predominantly confined to office end user stakeholders. Within this time, vendor consultants also supported the tailoring of the system to accommodate company idiosyncrasies. However, the later implementation of Company A's SFDC system, was done in isolation to vendor support, when the system became 'operational', there was much resistance to its use due to a general lack of knowledge about the system. As a result, when the system failed to deliver its anticipated benefits, the focus of the software selection and implementation team suddenly changed, from one of great expectation, to a process of blame apportioning. The Production Director claimed that the failure of the SFDC module was because: 


\begin{abstract}
" People were not informed of the impact the SFDC system would make to their job function(s) ... Nobody on the shop floor bought into ensuring the success of the system ... they needed educating not disciplining."
\end{abstract}

It soon became clear that training and education needed to be addressed to ensure project acceptance and success of investment initiatives. Operational stakeholders were unaware of the link between SFDC and PPC, which resulted in a unreliable Master Production Schedule (MPS). It was decided by the MD to enlist the support of a consultancy company, to facilitate the design, development, implementation and training of the workforce on ERP. Company A then instigated a series of intensive education sessions and workshop training days. All managers were educated on the importance of ERP and the impact that the investment would make to their job function(s). A simplified course was also developed for shop floor stakeholders. Education and training were used to promote teamwork and 'win over skeptics, with all employees mixed and grouped together to create a cross-functional stakeholder teamwork environment. This also encouraged knowledge and skills transfer associated with ERP, such as throughput production flow, communication, Just in Time (JIT), inventory management and Total Quality Management (TQM).

\title{
Management Commitment
}

Initially, there was considerable management commitment in Company A's implementation of vendor PPC/SFDC software. The project was championed by the MD, and when asked why other more directly affected managers were not responsible for leading the project, the MD replied:

"I was the main visionary leader and could see the long-term strategic implications of my decision to invest ... It was up to me to set the standard, and lead the way."

The MD/project champion quickly turned his attention, appearing to have either lost interest, due to implementation problems, or a lack of success, or being 'driven' by other organisational improvement initiatives. This raises the question of whether the MD was the most appropriate person to champion the project. Responsibility of the remaining implementation was then delegated to others, hoping that the by then well-established Production Director would take up the challenge. Interestingly, the Production Director was not a key member of the vendor PPC/SFDC implementation team but nevertheless, operated as an honoree, advising on technical issues when consulted. The Production Director was expected to take the lead. Although the Production Director acknowledged the contribution the PPC/SFDC system was making/could make towards the streamlining of the production function, he noted that is was never his project and that he did not relish the possibility of being responsible for mounting cost over-runs. However, the MD expressed an alternative opinion noting that the production director was always 'fire fighting' and reacting to day to day customer demands, being unable to detach himself and take a long-term strategic view of the company. Thus, there was much 'bad' feeling between the MD and production director, as a result of these expectations the Production Director questioned the commitment of the MD to own and be responsible for ensuring the details of the implementation were communicated correctly.

These concerns were exemplified when the system began to fail and the rest of the team felt that they lacked leadership, with the MD abdicating responsibility. However, when Company A decided to abandon the project and began developing bespoke ERP, many of the problems associated with management commitment were addressed. In doing so, the new project of bespoke system development was this time supported by the MD, with the Production Director now leading the project. This project was also facilitated through an external consultant. 


\section{ANALYSIS OF CASE DATA}

In analyzing the case data in the preceding sections, it can be seen that there exists a dichotomy of views relating to the issues faced. These views are principally based upon what can be said to be the expectations of management (i.e. the MD) as compared to end users of the ERP (i.e. the shop floor workers). In order to understand the dynamics involved within the evaluation context in the case company, the authors now define and delineate those aspects of the case data as related to explicit and tacit knowledge. Table 3 shows a summary of those positive and negative aspects of the ERP and ISE experiences in Company $A$. As can be clearly seen, there were unfortunately more negative aspects of this initiative than there were positive. The latter characteristics show that the company by and large recognized that change had to occur across all levels of the organisation in terms of people, process and technology. However, these factors were largely at the expense of losing focus and showing a lack of commitment on the details of stakeholder involvement, processes for ISE and communication and system rollout.

\section{Insert Table 3 here}

Furthermore, this given analysis compares favorably with available industrial management experience also, which highlights seven key ERP "problem areas": inadequate executive strategy; weak governance; lack of attention to business process management; lack of commitment to new support for process and system; organisational flaws or inadequacies; IT configuration issues; and infrastructure shortcoming (Welch et al., 2005). Thus, it can be seen that Company A exhibited most, if not all, of these qualities in its experiences. Hence, noting these contingent differences, Table 4 shows how each investment strategy facet can be analyzed in terms of explicit and tacit knowledge. In constructing this table, the authors sought to distill those given expectations of each stakeholder, that were ultimately articulated (i.e. made explicit) or were left unarticulated (were inherently tacit).

\section{Insert Table 4 here}

It is also interesting to compare and contrast each explicit and tacit drivers across each of the investment strategy facets. For example, with regards to Employee Commitment, there was a tacit assumption that any implementation of the SFDC module would imply performance management analysis (and hence potentially, a review of shop floor working practices and workers). This was clearly unfounded, but this perception existed as noted in the case data. If we compare this tacit knowledge assumption with the explicit Management Commitment drivers, we can see that it contrasts heavily with the strategic vision of the MD: to bring together people, processes and technology together (as quoted by the MD in the previous section on Cultural Issues). Also, there was an explicit expectation that a radical, technology-led change would change the culture of the company and make it more competitive.

However, the realization of this was found to be based upon tacit knowledge drivers which identified a relevant and important skills gap (thereby highlighting a focus on people, rather than IT/IS). There was an inherent and tacit "gap" between the change that was required and the skills that needed to be identified in order to reach that goal. In attempting to compare the case data with the SECI model, it can be seen that there is almost an interactive cycle and balance of explicit and tacit knowledge, within Table 4. This shows how one form of knowledge, was linked to the other. As such, the following section attempts to outline the extent of dependencies upon each decision, in terms of explicit and tacit knowledge. Thereby, allowing for a comparison with the Nonaka and Takeuchi SECI model of knowledge transformation. 


\section{Identification of Knowledge Dependencies and the SECI model}

As such, a mapping of these knowledge dependencies can be made against Nonaka and Takeuchi's SECI model defined earlier. This is shown in Figure 3.

\section{Insert Figure 3 here}

As mentioned previously, the purpose of carrying out this mapping to the SECI model, was to try and investigate in an exploratory sense, whether or not such a model can account for different forms of knowledge within an IS context. It is evident from the case data presented that those aspects of Organisational Culture (primarily stakeholder involvement and responsibility and skills) can be defined as existing in the Socialisation quadrant of the SECl model. Similarly, Management and Employee Commitment is placed in the Externalisation quadrant; IS within the Combination quadrant; and Training and Education in the Internalisation quadrant. This placement of these case data factors was carried out by attempting to reconcile each of these components with the definitions of the SECI model. For example, the externalisation of knowledge in the case company can be said to be manifested in terms of management and employee commitment, the detail of which involved / required this information to be transformed from explicit to tacit (i.e. understood) knowledge. This is further exemplified by the fact that management's strategic vision, although communicated, was not internalised and adopted by all the stakeholders.

By looking at the placement of the given factors identified, it can be noted that those aspects that are explicit, ultimately are dependent in some way on those that are tacit. For example, Organisational Culture can be said to implicitly influence Management and Employee Commitment (and vice versa); whilst Training and Education also influences and directs the level of IS adoption also. As such, this view of the IS lifecycle of the ERP system proves to be a useful tool in understanding and deciphering how each human and organisational aspect affects another. Thus, the latter components of this case were essentially hidden from all employees in Company A, as they were inherently tacit. But they only manifested themselves whence their related explicit counterpart component was realised. Thus, Management Commitment waned once it became clear that the Organisational Culture would not support leadership and communication of the firm's tactical / operational intent. IS adoption also had limited success due to a lack of training, as has been identified by the authors. Hence, in some sense, there was an interplay between each of these factors, which as the experience of the company shows, led to enterprise to reflect on its experiences post-hoc of the ERP and ISE tasks. Therefore, It would appear that there were some key organisational learning issues which Company $A$ realised as a result of this initiative. These are shown in Table 5 (derived from Irani et al., 2001).

\section{Insert Table 5 here}

The factors shown in Table 5 detail the fact that organisational structure and culture are implicitly linked with the adoption and implementation of an information systems solution. Although, the case study clearly highlights that business transformation is heavily reliant upon both change management and organisational learning, there is also an inherent emphasis on how given management decisions were arrived at - and the how the outcomes of those decisions were perceived. Indeed, it can be said that this observation supports the view taken by Edmondson, who found that learning from decisions and mistakes is implicitly linked to management's inability to communicate responsibility and overcome team tensions (Edmondson, 2004). Thus it can be surmised that Company $A$ learnt from its experiences in terms of reflecting upon changes it had to make to Organisational Culture, Employee and Management Commitment factors (thus implying a propensity for organisational learning). Additionally, both Training and Education and 
IS adoption were also noted by management as key factors to improve upon. In so doing, both the MD, Production and Purchasing Directors recognised the importance of formalizing both of these aspects via specific policies, processes and tools to facilitate them. As such, implying a knowledge management philosophy to be instigated at some point in the future. To elucidate these points further, the authors now place these research findings in the context of the ISE lifecycle, as described by Farbey et al., (1993) and is shown in Figure 4.

\section{Insert Figure 4 here}

In doing so, those factors outlined and found in this research have been aligned with each of the key components of Strategic Objectives (i.e. Management Commitment), Measurement (i.e. Training and Education, Benefits and Employee Commitment) and Organisational Learning (i.e. Cultural Issues and Organisational Culture). As such, these factors are external to the core IS evaluation and implementation lifecycle, but directly impinge upon it. When this is compared further to the SECI mapping in Figure 3, it can be seen that explicit as well as tacit knowledge factors are therefore inherent and implicit within the overall ISE process, in this regard. Thus signifying the fact, that in this case at least, no single factor drives the overall process. The application of the case data onto the SECI model tends to highlight and indeed aids in the categorisation of those drivers for ERP evaluation and implementation, within the case company. The authors therefore believe that by attempting to view those aspects of the ISE task using this lens, a better understanding of what drives the human, organisational and technological components of ERP investment can be gained.

\section{Learning Outcomes}

Company A could have well avoided its initial failure, if it had simply taken time to align and optimize its internal core competencies (skills and business operating mode), and seek advice on the efficacy of such an initiative. For example, Poor communication and discussion with shop floor representatives could have been avoided if management utilized a better communication strategy (maybe even enlisting the help of external professional services organisation for this). Also, a lack of cohesion amongst the senior management team could have been alleviated by agreeing on strategic goals, tactical fixes, and operational realities: setting and agree expectations and how they should be managed. Finally, and most crucially to the implementation of the ERP and effective use of internal technical organisational knowledge, the poor understanding of available ISE methods and how to use them, was a decision-making liability which may well have been easily addressed by doing more in-depth research and investigation into alternative ISE methods (which would fit the organisation better). Thus the following can be summarized:

- The case data shows and highlights that an interplay of human and organisational knowledge factors exist in this situation which resulted in:

- a lack of knowledge of other ISE techniques led to initial failure of implementing PPC/SFDC (being dependent upon the choice of CBA);

- emergence of a blame culture where management did not decisively communicate organisational objectives and responsibilities;

- a lack of planning for training and education which inhibited knowledge transfer and technology management.

- external assistance and support from vendor and professional services organisations was not sought and could have alleviated some of the issues experienced: learning how to make use of such services is critical (Sharif, 2002)

- Tacit issues were not made explicit (employee commitment and cultural issues festered; initial management decision-making, responsibility and commitment, as well as adequate training, was lacking) - this inhibited project success; 
- All stakeholders become franchised only when management realised the importance of transforming the explicit strategic vision into understandable, internalized knowledge (via the component of Training and Education).

- The SECI model was found to be a useful tool for describing this explicit-tacit knowledge transfer (although not in a strict knowledge transformation sense):

- Employee and Management commitment, as well Organisational Culture were seen as being factors useful for future organisational learning;

- Training and Education and ISE methods were also seen to be important factors to be codified and represented as part of the developing knowledge culture within the firm (i.e. as a precursor to a knowledge management paradigm).

\section{CONCLUSIONS}

This paper has attempted to investigate the nature of knowledge within the ISE task within a manufacturing case organisation. By seeing how the SECI model of Nonaka and Takeuchi (1995) can be applied to analyze knowledge within an IS context, it was noted that, ultimately, tacit ad-hoc decision making, belies explicit knowledge outcomes. In other words the (lack of) externalization of tacit management and employee behavioral commitment, had a direct effect on those aspects of Combination (IS adoption), Internalization (training), and Socialization (organisational culture) of the firm. As such, the given knowledge transformation involves factors relating to Organisational Culture, Management and Employee Commitment and ERP implementation skills and capabilities, in an alternating fashion. From the analysis of the case data, and a mapping of this data to the SECI model it appears that although there is no formal transformation of knowledge taking place, there is an interrelationship between the types of knowledge and technology implementation issues found in Company $A$. Thus the authors believe that the SECI model can be a useful tool in segmenting and classifying the constituent forms of explicit and tacit knowledge, and can lead to a useful discussion about the inter-relationships existing between different aspects of change-led business transformations.

The application of this model in this regard is not meant to be prescriptive in any sense. Rather it has been used in order to stimulate debate and further analysis of those knowledge factors and learning outcomes which may inherently drive and determine the outcome of ISE. Hopefully, it has been shown that mapping and identifying knowledge within such a context, can be a useful step in the IS evaluation and implementation lifecycle. The authors further believe that by applying complementary techniques and methodologies, such as those presented within this paper, this debate can be moved forward. As a result of the findings in this paper, there is scope for further investigation into those human and social factors which influence and catalyze concepts of organisational learning and knowledge management: effect of technologies on working practices; commitment of management; learning from other organisations; communication and learning; social contexts; dialogues and conversations; use of metaphors and story telling; and finally, the application and use of knowledge communities. It is hoped that this research will contribute to the basis for such future investigations in this regard.

\section{Acknowledgements}

The authors wish to gratefully acknowledge the support from the Information Systems Evaluation and Integration Group (ISEing) within which this work was carried out and upon which the research was based and supported. ISEing was established at Brunel University Department of Information Systems and Computing, in December 2000, under a research grant from the UK Engineering and Physical Sciences Research Council (EPSRC: GR/R08025/01). The authors would also like to acknowledge the Network for e-Government Integration and Systems Evaluation (e-GISE) (EPSRC: GR/T27020/01) and the financial support provided by the Australian Research Council. 


\section{REFERENCES}

BALLANTINE J and STRAY S (1999) Information systems and other capital investments: Evaluation practices compared. Logistics and Information Management, 12(1-2), 7893.

CARRIER L (1999) Managing at light speed. IEEE Compute, 32(7), July, 107-109.

CHAUVEL D and DESPRES C (2002). A review of survey research in Knowledge Management 1997 - 2001, Journal of Knowledge Management, 6 (3) : 207 - 223.

DAVENPORT TH and PRUSAK L (1998) Working Knowledge : How Organizations Manage What They Know. Harvard Business School Press, Boston.

DANE FC (1990) Research Methods. Brooks/Cole, Pacific Cole.

EDMONDSON A (2004) Learning from Mistakes is Easier Said than Done. Journal of Applied Behavioural Science, 40 (1), 66-90.

FARBEY B, LAND F, and TARGETT D (1993) How to Assess your IT investment: A study of methods and practices. Management Today. Butterworth-Heinemann, Oxford.

FIEDLER J (1978) Field Research: A Manual for Logistics and Management of Scientific Studies in Natural Settings. Jossey-Bass, San Francisco.

GALLIERS RD (1992) Choosing information systems research approaches. In Information Systems Research: Issues, Methods and Practical Guidelines (GALLIERS RD, Ed), pp 144-162, Blackwell Scientific, Oxford UK.

GOLDMAN SL, NAGEL RN, and PREISS K (1995) Agile Competitors and Virtual Organizations, Strategies for Enriching the Customer. Von Nostrand Reinhold, New York.

HOCHSTRASSER B, and GRIFFITHS C (1991) Controlling IT Investment: Strategy and Management. Chapman and Hall, London.

HOLSAPPLE CW and JOSHI KD (1999). Description and Analysis of existing knowledge management frameworks. In Proc. 32 $2^{\text {nd }}$ Hawaii Int. Conf. System Sciences (HICSS'99), Honolulu, Hawaii, USA, December 1999.

IRANI Z, EZINGEARD JN, and GRIEVE RJ (1997) Integrating the costs of an IT/IS infrastructure into the investment decision making process. The International Journal of Technological Innovation, Entrepreneurship and Technology Management (Technovation), 17 (11/12), 695-706.

IRANI Z, JONES S, LOVE PED, ELLIMAN T, JONES $S$ and THEMISTOCLEOUS $M$ (2005) Evaluating Information System Investments in Local Government: Drawing Lessons from Two Welsh Cases. Information Systems Journal, 15(1), 61- 82.

IRANI Z and LOVE PED (2001) The propagation of technology management taxonomies for evaluating information systems. Journal of Management Information Systems, 17(3), 161-177.

IRANI Z and LOVE PED (2002) Developing a frame of reference for ex-ante IT/IS investment evaluation. European Journal of Information Systems, 11(1), 74-82.

IRANI, Z, SHARP JM and KAGIOGLOU, M. (1997a). Improving business performance through developing a corporate culture. The International Bi-Monthly for Total Quality Management, The TQM Magazine, 9 (3), 206-216.

IRANI Z, SHARIF AM and LOVE PED (2001) Transforming failure into success through organizational learning: An analysis of a Manufacturing Information System. European Journal of Information Systems, 10(1), 55-66.

IRANI Z, THEMISTOCLEOUS M and LOVE PED (2003) The impact of enterprise application integration on information system lifecycles. Information and Management, 41(2), 177-187.

JANESICK V (2000) The choreography of qualitative research design In Handbook of qualitative research, (LINCOLN YS, Ed), pp 379-399, Sage Publications, Thousand Oaks.

KREINER K (2002). Tacit knowledge management: the role of Artifacts. Journal of Knowledge Management. 6 (2) : 112 - 123. 
LEONARD-BARTON D (1995). Wellsprings of Knowledge : Building and Sustaining the sources of Innovation. Harvard Business School Press : Boston, MA, USA.

MAYRING P (2000) Qualitative content analysis, Forum: Qualitative Social Research, $1(2), 1-80$.

MILES M.B and HUBERMAN A.M (1994) Qualitative data analysis: An expanded sourcebook ( $2^{\text {nd }}$ edition), Sage publication, Thousand Oaks.

NEWMAN B and CONRAD KW (1999). A Framework for characterizing Knowledge Management, methods, practices and technologies. In Proc. Documation '99, Toronto, Canada.

NONAKA I and TAKEUCHI H (1995). The Knowledge-creating Company: How Japanese Companies Create the Dynamics of Innovation. Oxford University Press, Oxford.

POLANYI M (1967) The Tacit Dimension. Doubleday-Anchor, New York.

PORTER M (1985) Competitive Advantage. Collier-MacMillan, New York.

PROBST G, RAUB S, and ROMHARDT K (2001). Managing Knowledge : Building Blocks for Success. John Wiley : Chichester, UK.

RANKY PG (1990) Manufacturing Database Management and Knowledge Based Expert Systems. CIMWare Ltd, Guildford, Surrey.

REMENYI D and SHERWOOD-SMITH M (1999) Maximise Information Systems value by continuous Participative Evaluation. Logistics Information Management, 12 (1/2), 1432.

REMENYI D, MONEY A, SHERWOOD-SMITH M, IRANI Z. 2000. 'The Effective Measurement and Management of IT Costs and Benefits'. Butterworth Heinemann, Second Edition, ISBN 075064420 6, UK.

SHARIF AM (2002) Professional Services Organisations and the role of Consulting in the New Economy. Information Systems Management, 19 (2), 19-30.

SHARIF AM and IRANI Z (2005) Emergence of ERPII characteristics within an ERP integration context. In Proceedings of $11^{\text {th }}$ Americas Conference on Information Systems $(A M C I S)$, August $11^{\text {th }}-14^{\text {th }}$, University of Omaha, Nebraska, USA.

SHARIF, A.M., IRANI., Z., AND LOVE, P.E.D. (2005). Integrating ERP with EAI: a model for post-hoc evaluation. European Journal of Information Systems, 14 (2): 162-174

SHAUGHNESSY, J.J., and ZECHMEISTER, E.B. (1994). Research Methods in Psychology. $3^{\text {rd }}$ Ed McGraw Hill, USA.

SHARP J.M, IRANI Z AND DESAI. S. (1999). Working towards agile manufacturing in the UK industry. International Journal of Production Economics, 62(5): 155-169.

SUCHMAN L (1987). Plans and Situated Actions: The Problem of Human-Machine Communication. Cambridge University Press : Cambridge, UK.

SVEIBY KE (1997) The New Organisational Wealth. Berret-Koehler, San Francisco.

TAPSCOTT D, LOWY A, TICOLL D, KLYM N (1998) Blueprint to the Digital Economy: Creating wealth in the era of E-Business. McGraw-Hill, New York.

THEMISTOCLEOUS M, IRANI Z, AND LOVE P.E.D. (2004). Evaluating the Integration of Supply Chain Information Systems. European Journal of Operational Research, 159(2): 393-405.

WALSHAM G (1995) The emergence of Interpretivism in IS research, Information Systems Research, 6(4), 376-394.

WEICK KE (1984). Theoretical assumptions and research methodology selection. In The Information Systems Research Challenge (McFARLAND FW, Ed), pp 111-132, Harvard Business School Press, Boston.

WHITLEY E (2002). Tacit and Explicit Knowledge: Conceptual Confusion around the Commodification of Knowledge. Department of Information Systems Working paper 90, London School of Economics and Political Science, London, UK.

WIIG KM (1997). Knowledge Management : An Introduction and Perspective. Journal of Knowledge Management, 1 (1) : 6-14.

YIN RK (1994)Case study research: Design and Methods ( $2^{\text {nd }}$ Edition), Sage Publications, Thousand Oaks. 

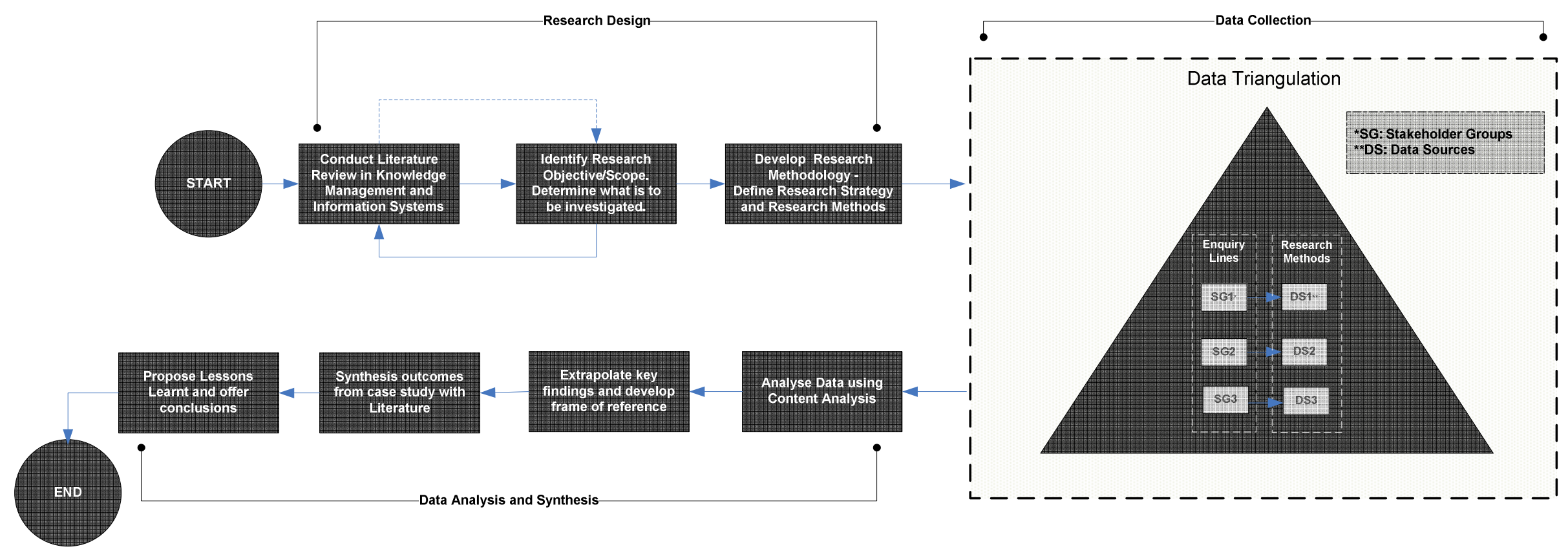

Figure 1. Research Methodology 


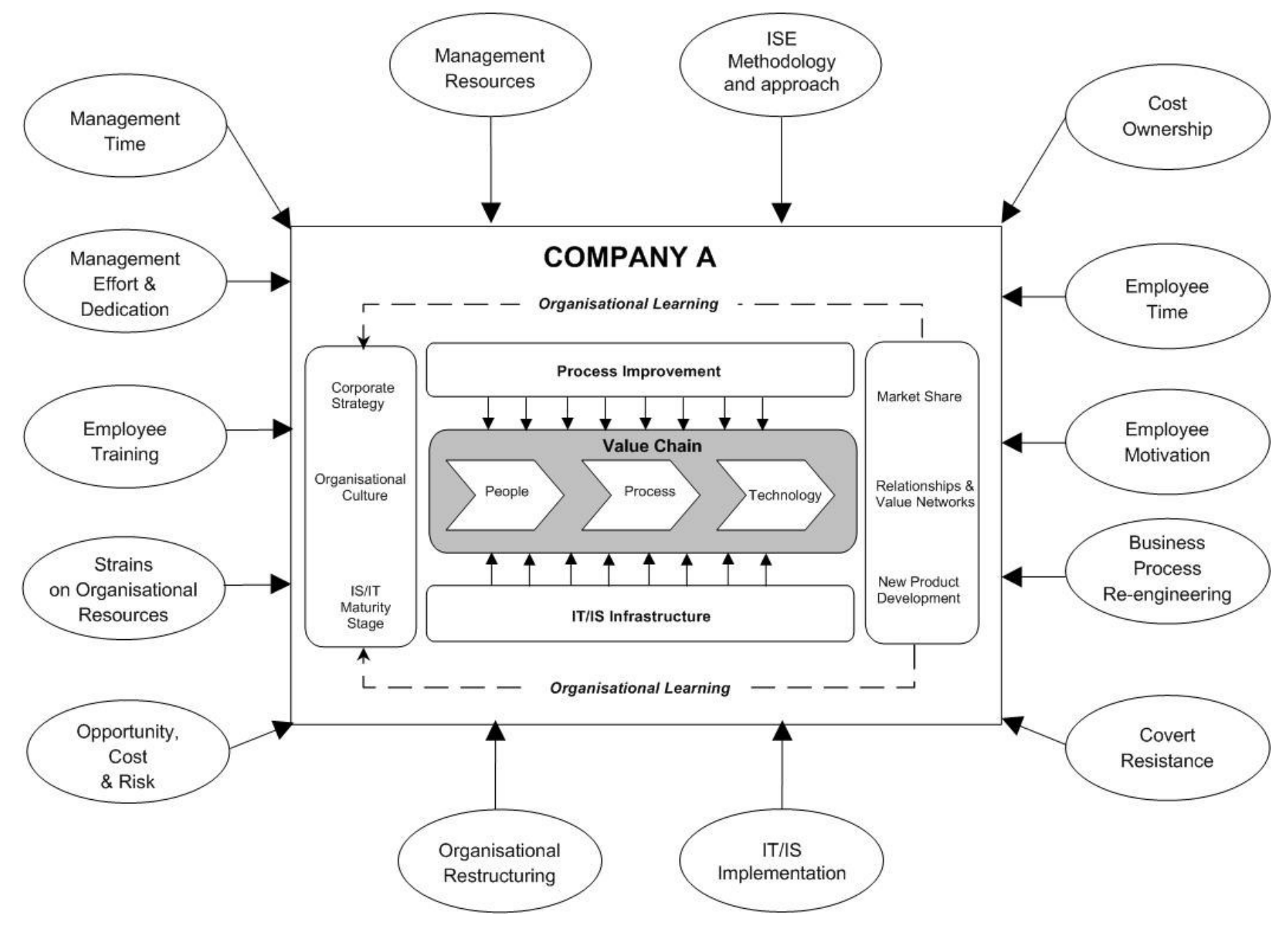

Figure 2. Context of Company A 


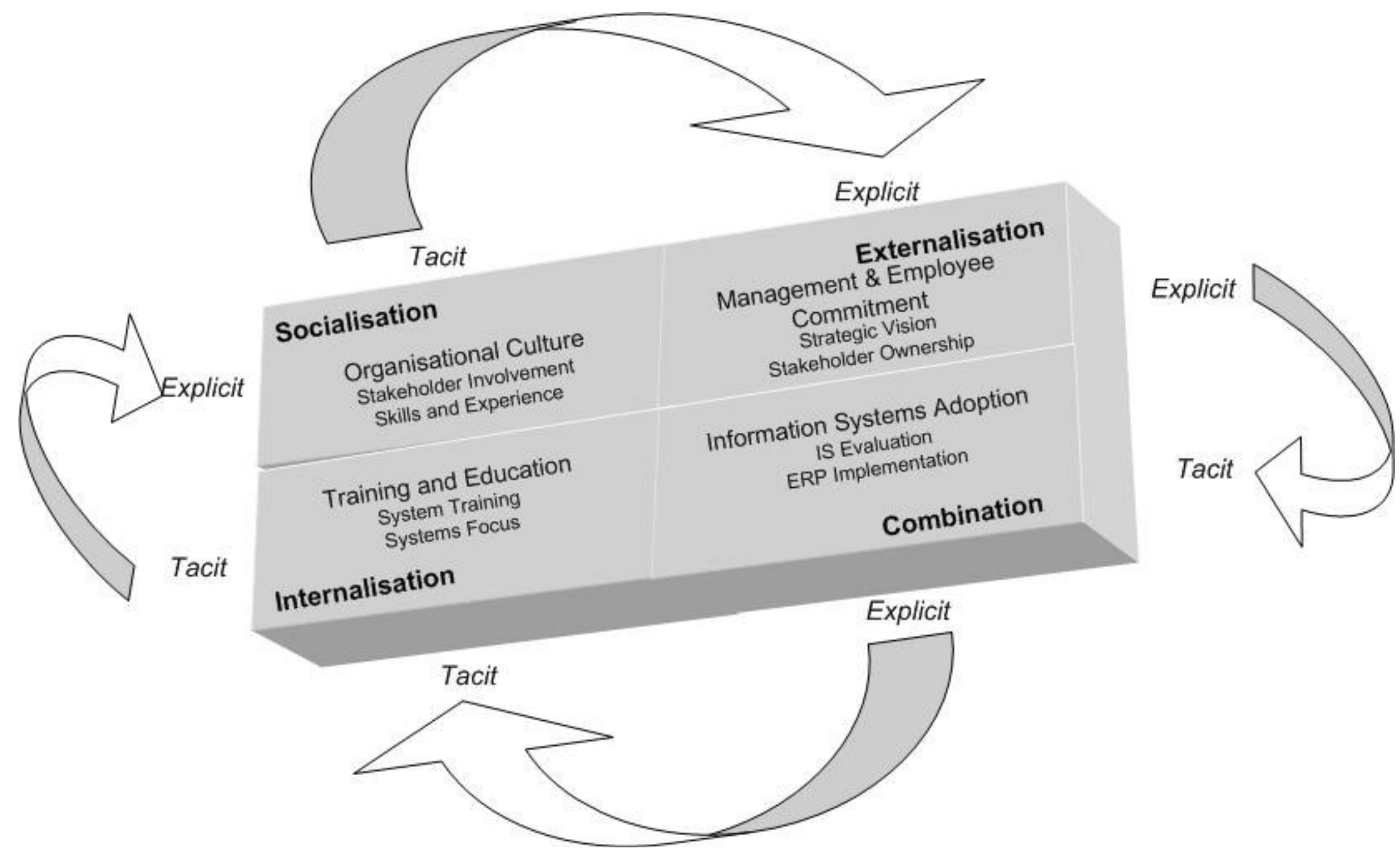

Figure 3. Mapping to the SECl model for Company A 


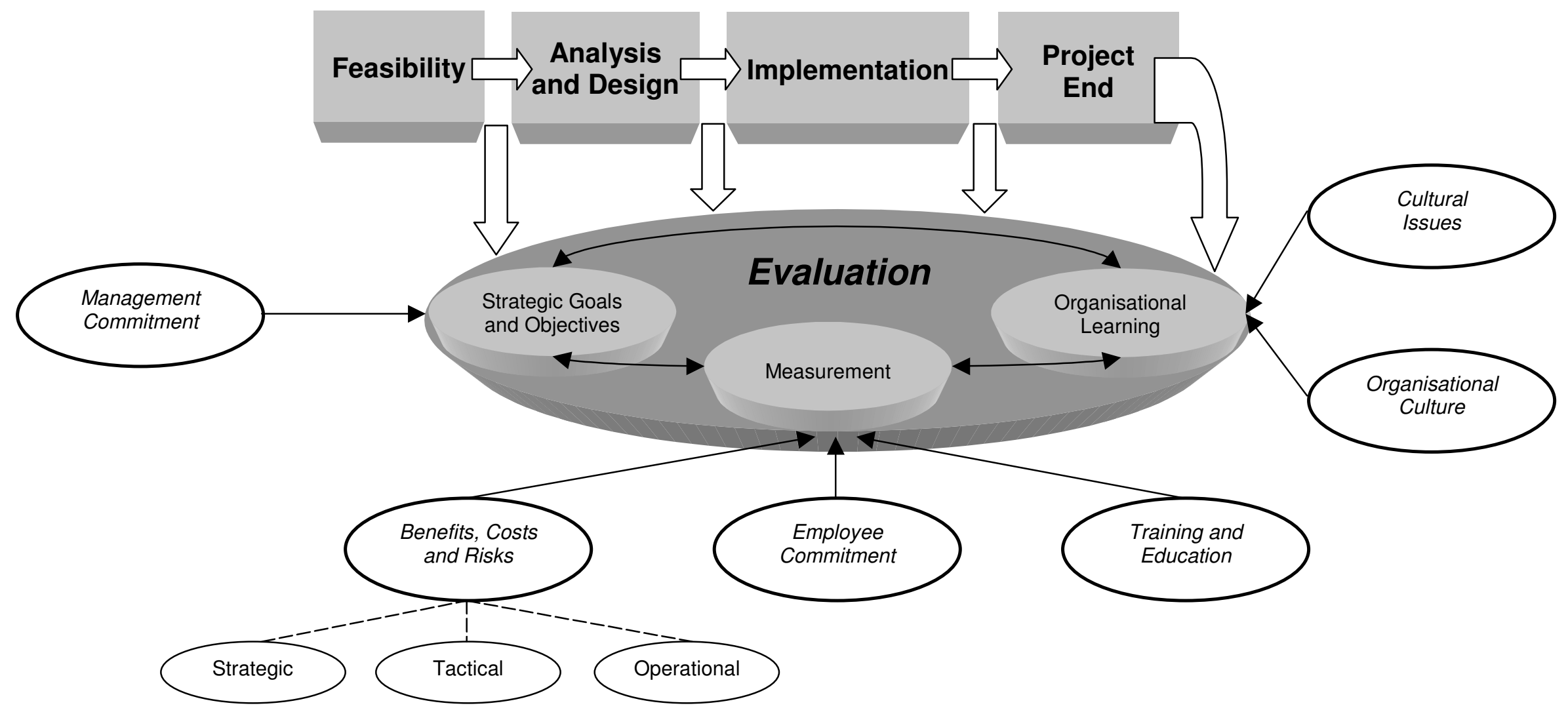

Figure 4. Knowledge components identified in Company A within the context of the ISE lifecycle (adapted from Farbey et al., 1993) 


\begin{tabular}{|c|c|c|c|}
\hline Classification & $\begin{array}{l}\text { Managing } \\
\text { Director }\end{array}$ & $\begin{array}{l}\text { Production } \\
\text { Director }\end{array}$ & $\begin{array}{l}\text { Purchasing } \\
\text { Director }\end{array}$ \\
\hline \multicolumn{4}{|c|}{ Strategic Benefits } \\
\hline Improved growth and success & $\checkmark$ & $\checkmark$ & $\checkmark$ \\
\hline Leader in new technology & $\checkmark$ & & $\checkmark$ \\
\hline Improved market share & $\checkmark$ & & $\checkmark$ \\
\hline Market leadership & $\checkmark$ & & $\checkmark$ \\
\hline Offer new strategic option & $\checkmark$ & $\checkmark$ & $\checkmark$ \\
\hline Competitive advantage & $\checkmark$ & $\checkmark$ & $\checkmark$ \\
\hline Improved response to customer changes & $\checkmark$ & $\checkmark$ & $\checkmark$ \\
\hline Improved product and service quality & $\checkmark$ & $\checkmark$ & $\checkmark$ \\
\hline Strategic product management and development & $\checkmark$ & & \\
\hline Improved organisational teamwork & $\checkmark$ & $\checkmark$ & $\checkmark$ \\
\hline Promotion of an 'open' proactive culture & $\checkmark$ & & \\
\hline Improved integration with other business functions & $\checkmark$ & $\checkmark$ & $\checkmark$ \\
\hline \multicolumn{4}{|c|}{ Tactical Benefits } \\
\hline Improved flexibility & $\checkmark$ & $\checkmark$ & $\checkmark$ \\
\hline Improved response to changes & & $\checkmark$ & \\
\hline Improved product and service quality & $\checkmark$ & $\checkmark$ & $\checkmark$ \\
\hline Improved organisational teamwork & & $\checkmark$ & $\checkmark$ \\
\hline Promotes concept of open proactive culture & $\checkmark$ & & $\checkmark$ \\
\hline Improved integration with other functions & $\checkmark$ & & $\checkmark$ \\
\hline Improved data management & & $\checkmark$ & \\
\hline Improved manufacturing control & $\checkmark$ & $\checkmark$ & $\checkmark$ \\
\hline Reduced manufacturing costs & $\checkmark$ & & $\checkmark$ \\
\hline Reduced manufacturing lead-times & $\checkmark$ & $\checkmark$ & $\checkmark$ \\
\hline Improved accuracy of decisions & $\checkmark$ & $\checkmark$ & $\checkmark$ \\
\hline $\begin{array}{l}\text { Platform for efficient and effective business } \\
\text { processes by recording specific transactions }\end{array}$ & & $\checkmark$ & \\
\hline $\begin{array}{l}\text { Improved management information and analysis, } \\
\text { and performance monitoring }\end{array}$ & & & $\checkmark$ \\
\hline \multicolumn{4}{|c|}{ Operational Benefits } \\
\hline Availability of info to customer facing staff & & $\checkmark$ & $\checkmark$ \\
\hline Improved capacity planning & $\checkmark$ & $\checkmark$ & $\checkmark$ \\
\hline Improved stability of MPS & & $\checkmark$ & \\
\hline Increased productivity & $\checkmark$ & & \\
\hline Increased plant efficiency & $\checkmark$ & $\checkmark$ & $\checkmark$ \\
\hline Reduced delivery lead-times & $\checkmark$ & $\checkmark$ & $\checkmark$ \\
\hline Reduced levels of WIP & $\checkmark$ & $\checkmark$ & $\checkmark$ \\
\hline Reduced labor costs & $\checkmark$ & & $\checkmark$ \\
\hline Increased throughput & $\checkmark$ & & $\checkmark$ \\
\hline Improved data availability and reporting & & $\checkmark$ & $\checkmark$ \\
\hline Improved communication through part tracking & & $\checkmark$ & \\
\hline Improved product traceability & & $\checkmark$ & \\
\hline Formalised production & & $\checkmark$ & \\
\hline Enhanced, or speeding up of data entry & & $\checkmark$ & $\checkmark$ \\
\hline
\end{tabular}

Table 1. Taxonomy of Strategic, Tactical and Operational ERP Benefits at Company A 


\begin{tabular}{|c|c|c|c|c|c|c|c|c|c|}
\hline & $\begin{array}{l}\text { Type of } \\
\text { initiative }\end{array}$ & $\begin{array}{l}\text { Typical ISE } \\
\text { approach }\end{array}$ & Priority & $\begin{array}{l}\text { Resource } \\
\text { allocation }\end{array}$ & $\begin{array}{c}\text { Business } \\
\text { Process } \\
\text { Change }\end{array}$ & $\begin{array}{l}\text { Assumed } \\
\text { Benefits }\end{array}$ & $\frac{\text { Business }}{\text { Vision }}$ & Management & $\frac{\text { Typical IT/IS }}{\text { Solution }}$ \\
\hline Innovation & $\begin{array}{l}\text { Strategic } \\
\text { programme / } \\
\text { functionally } \\
\text { aligned portfolio } \\
\text { of tactical } \\
\text { projects }\end{array}$ & $\begin{array}{l}\text { Multi-year } \\
\text { budget, } \\
\text { validated every } \\
\text { planning cycle }\end{array}$ & $\begin{array}{l}\text { Aligned with } \\
\text { achieving } \\
\text { maximum, market- } \\
\text { leading benefits; } \\
\text { Solving greatest } \\
\text { perceived problems } \\
\text { at the time }\end{array}$ & $\begin{array}{c}\text { Assign / re- } \\
\text { assign after } \\
\text { project is } \\
\text { completed }\end{array}$ & $\begin{array}{c}\text { High } \\
\text { probability of } \\
\text { change } \\
\text { required }\end{array}$ & $\begin{array}{l}\text { High Value } \\
\text { and on-going } \\
\text { but with Risk }\end{array}$ & Very clear & $\begin{array}{c}\text { Highly } \\
\text { Desirable }\end{array}$ & $\begin{array}{l}\text { ERP, } \\
\text { SCM }\end{array}$ \\
\hline Support & $\begin{array}{l}\text { Steady stream } \\
\text { of support } \\
\text { services } \\
\text { (general } \\
\text { infrastructure, } \\
\text { production } \\
\text { machinery, } \\
\text { planning } \\
\text { resources, IT/IS } \\
\text { infrastructure) }\end{array}$ & $N / A$ & None applied & No & None & $\begin{array}{c}\text { Necessity to } \\
\text { business } \\
\text { survival }\end{array}$ & $\mathrm{N} / \mathrm{A}$ & $\begin{array}{l}\text { Costs should } \\
\text { reduce over } \\
\text { time for a } \\
\text { given level of } \\
\text { support }\end{array}$ & CNC \\
\hline
\end{tabular}

Table 2.

Company A project appraisal framework 


\begin{tabular}{|c|c|c|}
\hline Aspect & Positive Aspects Identified & Negative Aspects Identified \\
\hline Employee Commitment & $\begin{array}{l}\text { - Identified processes to be streamlined } \\
\text { - Technical issues addressed in detail }\end{array}$ & $\begin{array}{l}\text { - Did not consult stakeholders widely } \\
\text { - No shopfloor representatives on vendor selection team } \\
\text { - Human issues were not considered in line with technical } \\
\text { issues } \\
\text { - Did not address reservations about resistance to change } \\
\text { - Did not communicate fully with stakeholders about IT/IS } \\
\text { change }\end{array}$ \\
\hline Organisational Culture & $\begin{array}{l}\text { - Realised and streamlined senior management structure } \\
\text { - Radical change in order to transform company fortunes } \\
\text { and make it more competitive } \\
\text { - Eventual realignment and focus onto people rather than } \\
\text { purely IT/IS issues }\end{array}$ & $\begin{array}{l}\text { - Management void created by removal of two senior } \\
\text { directors } \\
\text { - Too much change too soon, leading to mistrust in } \\
\text { authority and ability }\end{array}$ \\
\hline Training and Education & $\begin{array}{l}\text { - Consultancy brought in to address training and education } \\
\text { shortcomings } \\
\text { - In-house intensive courses for all levels of the organisation } \\
\text { - Group learning encouraging knowledge transfer }\end{array}$ & $\begin{array}{l}\text { - Initially, lack of training and education plans } \\
\text { - Implementation and training done without vendor support } \\
\text { for SFDC module } \\
\text { - Lack of formalisaion of systems } \\
\text { - Lack of basic Computer Integrated Manufacturing (CIM) } \\
\text { knowledge by stakeholders hampered effective use of } \\
\text { systems and processes (SFDC, PPC, MPS) }\end{array}$ \\
\hline
\end{tabular}

Table 3. 


\begin{tabular}{|c|c|c|}
\hline $\begin{array}{c}\text { Investment Strategy } \\
\text { Facet }\end{array}$ & $\begin{array}{l}\text { Explicit Knowledge } \\
\text { Drivers }\end{array}$ & $\begin{array}{l}\text { Tacit Knowledge } \\
\text { Drivers }\end{array}$ \\
\hline Employee Commitment & $\begin{array}{l}\text { - Stakeholder processes } \\
\text { - In-house and external } \\
\text { implementation support }\end{array}$ & $\begin{array}{l}\text { - Stakeholder ownership } \\
\text { - Performance management } \\
\text { metrics }\end{array}$ \\
\hline Organisational Culture & $\begin{array}{l}\text { - Radical change } \\
\text { - Technology-led }\end{array}$ & $\begin{array}{l}\text { - Experience and skills gap } \\
\text { - People-focussed }\end{array}$ \\
\hline Training and Education & $\begin{array}{l}\text { - Targetted system training } \\
\text { - Systems focus }\end{array}$ & $\begin{array}{l}\text { - Stakeholder identification } \\
\text { - Skills identification }\end{array}$ \\
\hline Management Commitment & $\begin{array}{l}\text { - Strategic Vision } \\
\text { - Programme Management }\end{array}$ & $\begin{array}{l}\text { - Operational delegation } \\
\text { - Tactical decision-making }\end{array}$ \\
\hline
\end{tabular}

Table 4. Explicit and Tacit knowledge drivers within Company A

\begin{tabular}{|c|c|}
\hline Organisational Learning Factors & Critical Success Factors (CSFs) \\
\hline $\begin{array}{l}\text { - Organisational culture and management } \\
\text { commitment facilitates synergy between } \\
\text { people, processes and technology } \\
\text { - Implementation success realised via an } \\
\text { understanding of people issues first, } \\
\text { then IT/IS issues } \\
\text { - IT/IS evaluation against qualitative } \\
\text { factors, should be part of the change } \\
\text { management philosophy in } \\
\text { manufacturing organisations: } \\
\text { management and workforce buy-in, will } \\
\text { underpin, initiate and maintain } \\
\text { enterprise growth as a result. }\end{array}$ & $\begin{array}{l}\text { - Support from management through clear } \\
\text { communication of responsibilities and } \\
\text { decision-making outcomes } \\
\text { - An understanding of the business fit of the } \\
\text { new technology. } \\
\text { - Training, development and encouragement } \\
\text { of individuals throughout all levels of the } \\
\text { organisation. }\end{array}$ \\
\hline
\end{tabular}

Table 5. Organisational Learning issues faced by Company A 